\begin{tabular}{|c|c|}
\hline Title & Characterisation and properties of visible light- active bismuth oxide titania composite photocataly sts \\
\hline Author(s) & Ratova, M.; Tosheva, L.; Kelly, P. J.; Ohtani, B. \\
\hline Citation & $\begin{array}{l}\text { Sustainable materials and technologies, } 22, \text { e00112 } \\
\text { https://doi.org/10.1016/.susmat.2019.e00112 }\end{array}$ \\
\hline Issue Date & 2019-12 \\
\hline DOC URL & http:/hdl.handle.net/2115/83380 \\
\hline Rights & $\begin{array}{l}\text { (9 2019, Elsevier. Licensed under the Creative Commons A ttribution-NonCommercial-NoDerivatives } 4.0 \text { International } \\
\text { http://creativecommons.org/icenses/by-nc-n/4.0/ }\end{array}$ \\
\hline Rights(URL) & http://creativecommons.org/icenses/by-nc-nd/4.0/ \\
\hline Type & article (author version) \\
\hline File Information & Manuscript TiO2-BiOx - final.pdf \\
\hline
\end{tabular}

Instructions for use 


\section{Characterisation and properties of visible light-active bismuth oxide-titania composite photocatalysts}

M. Ratovaa*, L. Tosheva ${ }^{\text {b }}$, P.J. Kelly ${ }^{\text {a }}$, B. Ohtani ${ }^{\mathrm{c}}$

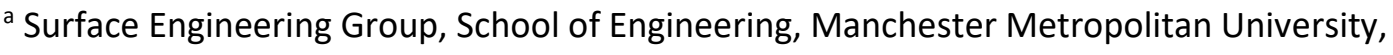
Manchester, M1 5GD, UK

${ }^{\mathrm{b}}$ School of Science and Environment, Manchester Metropolitan University, Manchester, M1 5GD, UK 'Institute for Catalysis, Hokkaido University, Sapporo 001-0021, Japan

* Corresponding author: M. Ratova, School of Engineering, Manchester Metropolitan University, John Dalton Building, Chester Street, Manchester M1 5GD, UK, tel. +44 161247 4648, e-mail address marina ratova@hotmail.com

\section{Abstract}

Bismuth oxide - titanium dioxide composite materials were produced by pulsed DC reactive magnetron sputtering onto two types of commercially available titanium dioxide nanoparticles. The use of an oscillating bowl enabled deposition of bismuth oxide uniformly onto loose powders, in contrast to solid substrates typically used for the conventional magnetron sputtering processes. Variation of the deposition time allowed the production of composite materials with different amounts of bismuth oxide. The composite materials, as well as uncoated titania powders, were extensively analysed by a range of analytical techniques, including SEM/EDX, XRD, BET, XPS, TEM and UV-visible diffuse reflectance spectroscopy. Photocatalytic properties of the materials were assessed under simulated visible light irradiation via degradation of acetone and methanol through measurements of carbon dioxide evolution. Additionally, the composite materials were characterised with a newly developed technique of reversed double-beam photoacoustic spectroscopy in order to obtain information on the distribution of electron traps. Bismuth oxide was 
found in crystalline $\beta-\mathrm{Bi}_{2} \mathrm{O}_{3}$ form on both types of substrates without any additional heat treatment applied. Though the distribution of bismuth oxide on titanium dioxide was found to depend strongly on particle size and deposition time used, the composite materials exhibited significantly enhanced visible light photocatalytic activity compared to either of the commercial titania materials used as a substrate.

Keywords: photocatalysis; titanium dioxide; bismuth oxide; visible light; magnetron sputtering.

\section{Introduction}

Over the past few decades photocatalysis has gained recognition as promising method of air, water and surface depollution and decontamination. Of the wide range of photocatalytic materials investigated since the discovery of photoelectrochemical water splitting on a photoirradiated singlecrystal rutile electrode in 1969 [1], titanium dioxide (or titania) still remains the most studied and widely used photocatalytic material, owing to its low cost, high chemical stability and non-toxicity. However, at the same time, the practical use of titanium dioxide is rather limited due to a number of significant drawbacks associated with the use of this material. Thus, unmodified titanium dioxide has shown relatively low quantum efficiency due to the rate of charge-carrier recombination being higher than charge transfer to the substrate. Also, pristine titanium dioxide is characterised with rather high energy gap ( $3.2 \mathrm{eV}$ for anatase phase), and therefore can only be photoactivated using light with wavelengths $<387 \mathrm{~nm}$ (that constitutes less than $5 \%$ of the total solar-spectrum energy). Therefore, in modern photocatalysis-related research, a considerable amount of work is dedicated to modifying titanium dioxide in order to improve quantum efficiency and narrow the band gap to enable photoactivation with visible/solar light. The widely reported techniques to introduce the latter changes include doping titania with metallic elements and-/-or non-metals, photosensitization and coupling titanium dioxide with the other semiconducting materials, with either wider or narrower band gaps [2-6]. 
While the idea of coupling titanium dioxide with another semiconductor is not new, the choice of the other semiconductor to be coupled with $\mathrm{TiO}_{2}$ is still rather debatable. Of the low band gap semiconducting materials, bismuth-based materials have attracted considerable attention over the past few years [7]; due to the strong oxidative abilities their significance for environmental chemistry processes have been confirmed in a number of reports $[8,9]$ Bismuth (complex) oxides, including bismuth tungstate [10-12], bismuth molybdate [13-15], bismuth titanate [16] and bismuth vanadate $[17,18]$, are subject to extensive research efforts. A number of them have been reported as photocatalytic materials in their own right, while the others are still mainly used for photosensitizing titania. However, compared to bismuth complex oxides, bismuth oxide, $\mathrm{Bi}_{2} \mathrm{O}_{3}$, has not been so widely studied. Even though several works report bismuth oxide as a narrow band gap semiconducting material with photocatalytic properties under visible light irradiation $[10,19,20]$, the number of studies using $\mathrm{Bi}_{2} \mathrm{O}_{3}$ for coupling with $\mathrm{TiO}_{2}$ is still rather limited. However, the available works clearly reflect the potential of such a composite material.

Composite materials of bismuth oxide and titania have been demonstrated to date as being able to degrade various model pollutants, including dyes [21-25], phenol [26, 27], toluene [28], various pharmaceuticals $[29,30]$ and pesticides [31] under visible and solar irradiation. These materials may be used in powdered form [23, 24, 30,32], as well as in the form of solid coatings [27, 33, 34]. Of the preparation methods, these materials are the most frequently synthesized using the sol-gel method $[22,23,25,34]$, hydrothermal synthesis [24, 33, 35, 36], or a combination of both [26].

However, as can be seen from the literature review presented above, the absolute majority of the bismuth oxide-titania composite materials reported to date were synthesized using solely chemical methods, which may limit their commercial exploitation. In contrast to that, magnetron sputtering is a physical vapour deposition method, which is currently an industrial process of choice for various functional films [37], including photocatalytic ones. The method provides such obvious advantages, in comparison to chemical methods, as; no requirement for toxic or hazardous precursors, an 
absence of hazardous process by-products, excellent control over uniformity and composition and great up-scaling potential. Despite the fact that magnetron sputtering is typically used for deposition of coatings onto flat substrates, the authors of the present paper have recently shown that it can be readily used for deposition of functional coatings onto particulates of various shapes and sizes, from several millimeters in diameter [10], to nanoparticulates [10, 38].

Therefore, in the present work we report the production of the bismuth oxide-titania composites based on commercially available $\mathrm{TiO}_{2}$ photocatalysts, using a one-step reactive magnetron sputtering technique. Therefore, the production method we present here is readily up-scalable, likewise other magnetron sputtering-related studies, and moreover the composite materials do not require any post-deposition calcination step, making the technique highly relevant for cost-efficient production of visible light-activated photocatalysts, based on the use of commercially available titania photocatalytic particulates. The composite materials produced, unlike uncoated titania powders, have been shown to be efficient visible light photocatalysts. The samples studied have been extensively characterised with a range of analytical techniques. Moreover, a powerful newly developed technique of reversed double-beam photoacoustic spectroscopy (RDB-PAS) [39-41] was employed for assessment of the energy-resolved distribution of electron traps, reportedly for the first time for titanium dioxide - bismuth oxide composites.

\section{Experimental}

\subsection{Deposition process}

Bismuth-oxide coatings were deposited in a one-step process in an arrangement similar to the one described in detail earlier $[10,42]$. In brief, the vacuum coating system includes two planar $300 \times$ $100 \mathrm{~mm}^{2}$ unbalanced type II magnetrons installed on the top of the vacuum chamber in a closed field, sputter-down configuration. The bismuth target ( $99.5 \%$ purity, bonded to a copper backing plate) was installed on one magnetron, while the other was shielded and used just for closing the magnetic field lines between the magnetrons [37]. The substrate holder comprising the oscillating 
bowl mechanism was placed underneath the magnetrons. The $450 \mathrm{~mm}$ flat-bottomed bowl mounted on the oscillator is used for the manipulation of the nanoparticles to be coated; this is achieved by a combination of vertical oscillations at $50 \mathrm{~Hz}$ with a lateral twisting moment introduced by springs connected between the electromagnet and the base plate of the oscillator [38]. As reported earlier, the latter results in uniform coverage of the moving particles with the coating flux as they traverse around the bowl.

The sputtering process was facilitated in reactive mode in an argon / oxygen atmosphere at a partial pressure of 0.4 $\mathrm{Pa}$. The gas flow was controlled with mass flow controllers; an argon flow of $15 \mathrm{sccm}$ and oxygen flow of $20 \mathrm{sccm}$ were used for all sputtering runs. Power to the magnetron was delivered in pulsed DC mode (pDC) using an Advanced Energy power supply; power of 300W, pulse frequency of $100 \mathrm{kHz}$ and $50 \%$ duty cycle were used for all sputtering runs, while deposition times were varied.

For each deposition run, either a 10g charge of titanium dioxide CristalACTiV ${ }^{\mathrm{TM}}$ PC500 (Cristal Global) or a $2 \mathrm{~g}$ charge of titanium dioxide P25 (Sigma Aldrich) was placed to the bowl - the amount of the titania particles was selected based on the oscillator bowl volume limitation. No additional substrate heating was used; and, as identified with temperature-sensitive crayons, the process temperature did not exceed $373 \mathrm{~K}$ (the deposition times were chosen to prevent significant substrate heating and therefore ensure that deposition process does not result in the phase modifications of the substrate). The summary of the variable deposition parameters is provided in Table 1.

\subsection{Characterisation}

The morphology and composition of the composite samples were analysed with scanning electron microscopy (SEM) coupled with energy dispersive X-ray spectroscopy (EDX) (EDAX Trident installed on a Zeiss Supra 40 VP-FEG-SEM). Crystallographic information of the coatings was obtained with Xray diffractometry (XRD) (Panalytical Xpert diffractometer with CuKa1 radiation at $0.154 \mathrm{~nm}$ over the range of 20 to $80^{\circ} 2 \theta$; the accelerating voltage and applied current were $40 \mathrm{kV}$ and $30 \mathrm{~mA}$, 
respectively). The X-ray photoelectron spectroscopy (XPS) was performed using an AMICUS photoelectron spectrometer (Kratos Analytical Ltd.) equipped with an Mg K X-ray as the primary excitation source. The binding energy was referenced to the C $1 \mathrm{~s}$ line at $284.8 \mathrm{eV}$ for calibration. Curve fitting was performed using a Gaussian function with a Shirley background. Transmission electron microscopy (TEM) images were obtained on a FEI Titan Themis 300 operated at 300kV fitted with the Super-X EDX system with windowless 4-detector design and 0.7 srad solid angle and the Gatan OneView 16 Megapixel CMOS digital camera. Optical properties of the samples were studied by UV-vis spectroscopy using a Cary 100 UV-vis spectrophotometer equipped with an internal G9830 diffuse reflectance accessory (Agilent Technologies) with white USRS-99-010 standard reference material for background correction. The specific surface areas of the samples were determined with Brunauer-Emmett-Teller (BET) surface area measurements, which were made using a Micromeritics ASAP2020 system. Samples were heated for $12 \mathrm{~h}$ at $300^{\circ} \mathrm{C}$ prior to analysis and surface areas were calculated from nitrogen adsorption data in the range of relative pressures between 0.05 and 0.3 using the BET model.

\subsection{Photocatalytic activity assessment}

The photocatalytic activity of the composite materials was assessed via photodegradation of acetone and methanol under visible light irradiation. In brief, a fixed amount of sample was spread over a $55 \mathrm{~mm}$ glass petri plate and placed into a purpose-built reaction cell (detailed description of the testing procedure is given elsewhere [42]); $1 \mathrm{ml}$ of liquid acetone or methanol (all reagents used in this work were purchased from Sigma-Aldrich, unless stated otherwise) was injected into the cell with a syringe. The testing cell was kept in the dark for 30 min to reach adsorption-desorption equilibrium and then exposed to the visible light irradiation for a total time of 1 hour. The visible light source was simulated by the combined use of $2 \times 15$ W Ushio fluorescent lamps with a $395 \mathrm{~nm}$ log-pass filter from Knight Optical. The emission spectrum of the simulated visible light source recorded with Ocean Optics USB4000 UV-visible spectrometer is shown in the Figure 1. 


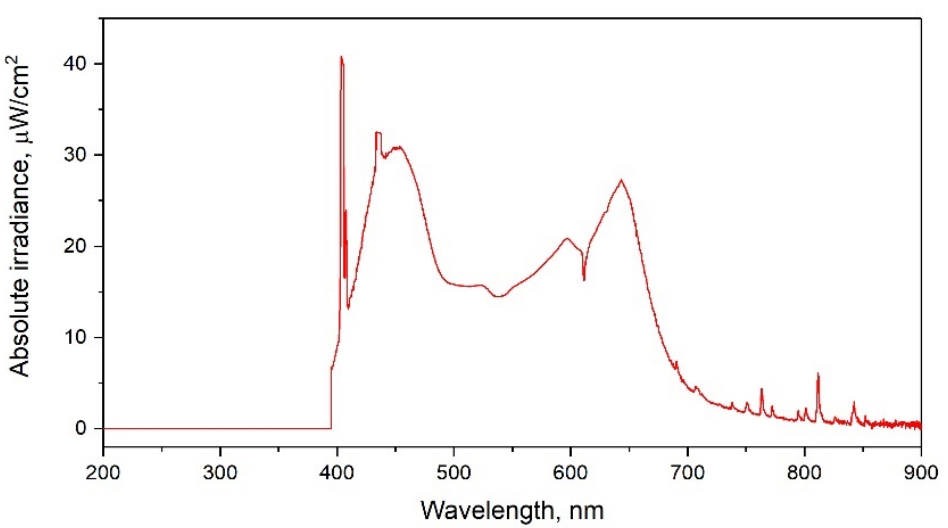

Figure 1. Spectrum of the fluorescent light source used for photocatalytic testing (with 395nm long-pass filter).

Therefore, it is evident that photocatalytic degradation of the volatile organic compounds used as model pollutants in the present work can be monitored via evolution of carbon dioxide. $\mathrm{CO}_{2}$ concentration was measured with a Vaisala CARBOCAP ${ }^{\circledR}$ carbon dioxide meter used with a Vaisala GM70 2000 ppm probe incorporated into the reaction cell. Photocatalytic activity of unmodified titanium dioxide powders, PC500 and P25, was assessed for comparison purposes. A series of reference tests was carried out prior to the photocatalytic activity measurements, including a blank test under the visible light source (no sample in the reaction cell), and tests of each sample under dark conditions. Neither of the reference tests showed a detectable increase in carbon dioxide level, therefore these results were neglected in the further evaluation of photocatalytic activity.

All repeated tests of each sample were performed using the same weighed measure of material; between experiments the test cell was purged with compressed air and held for $30 \mathrm{~min}$ in the dark to allow adsorption-desorption equilibrium to be reached before each measurement.

\subsection{Measurement of energy-resolved distribution of electron traps (reversed double-beam} photoacoustic spectroscopy (RDB-PAS))

For measurements of the energy-resolved distribution of electron traps (ERDT), a stainless steel sample holder was filled with a sample and set in a home-made photoacoustic (PA) cell equipped 
with a MEMS microphone and a quartz window on the upper side (detailed experimental description can be found elsewhere [43]). The PA cell was filled with methanol-saturated argon, and two light beams were applied simultaneously using a UV quartz combined light guide; a $625 \mathrm{~nm}$ wavelength beam came from a LED modulated by a digital function generator at $80 \mathrm{~Hz}$, while a monochromator was used for delivery of continuous monochromatic light with a wavelength scanning from 650 to $350 \mathrm{~nm}$ with $5 \mathrm{~nm}$ steps. The raw spectrum was differentiated from the lower-energy side and calibrated with the reported total electron-trap density in units of $\mu \mathrm{mol} \mathrm{g}^{-1}$ measured by a photochemical method to obtain an ERDT pattern. Using the same PAS cell, an ordinary single-beam PA spectrum was also measured to evaluate band gap, i.e., conduction band-bottom (CBB) energy in reference to valence band top (VBT), of a sample.

\section{Results and discussion}

Table 1. Summary of deposition conditions, composition, crystal phase and surface area information

\begin{tabular}{|c|c|c|c|c|c|c|}
\hline Sample ID & Substrate & $\begin{array}{l}\text { Mass of } \\
\text { substrate, } \\
\text { g }\end{array}$ & $\begin{array}{l}\mathrm{Bi}_{2} \mathrm{O}_{3} \\
\text { deposition } \\
\text { time, min }\end{array}$ & $\begin{array}{l}\text { Crystal } \\
\text { phase }\end{array}$ & $\begin{array}{l}\text { Bi content, } \\
\text { at.\% }\end{array}$ & $\begin{array}{l}\text { BET } \\
\text { surface } \\
\text { area, } \mathrm{m}^{2} / \mathrm{g}\end{array}$ \\
\hline PC500 & $\mathrm{TiO}_{2} \mathrm{PC} \mathrm{OOO}$ & 10 & --- & Anatase & --- & 325 \\
\hline PC500Bi15 & $\mathrm{TiO}_{2} \mathrm{PC} 500$ & 10 & 15 & Anatase & 0.22 & 316 \\
\hline PB500Bi30 & $\mathrm{TiO}_{2} \mathrm{PC500}$ & 10 & 30 & $\begin{array}{l}\text { Anatase } \\
\text { / } \\
\text { bismuth } \\
\text { oxide }\end{array}$ & 0.42 & 301 \\
\hline PC500Bi60 & $\mathrm{TiO}_{2} \mathrm{PC500}$ & 10 & 60 & $\begin{array}{l}\text { Anatase } \\
\text { / }\end{array}$ & 0.78 & 297 \\
\hline
\end{tabular}




\begin{tabular}{|c|c|c|c|c|c|c|}
\hline & & & & $\begin{array}{l}\text { bismuth } \\
\text { oxide }\end{array}$ & & \\
\hline $\mathrm{P} 25$ & $\mathrm{TiO}_{2} \mathrm{P} 25$ & 2 & --- & $\begin{array}{l}\text { Anatase } \\
\text { / rutile }\end{array}$ & --- & 54 \\
\hline P25Bi15 & $\mathrm{TiO}_{2} \mathrm{P} 25$ & 2 & 15 & $\begin{array}{l}\text { Anatase } \\
\text { / rutile / } \\
\text { bismuth } \\
\text { oxide }\end{array}$ & 0.40 & 58 \\
\hline P25Bi30 & $\mathrm{TiO}_{2}$ P25 & 2 & 30 & $\begin{array}{l}\text { Anatase } \\
\text { / rutile / } \\
\text { bismuth } \\
\text { oxide }\end{array}$ & 0.74 & 60 \\
\hline P25Bi60 & $\mathrm{TiO}_{2}$ P25 & 2 & 60 & $\begin{array}{l}\text { Anatase } \\
\text { / rutile / } \\
\text { bismuth } \\
\text { oxide }\end{array}$ & 1.58 & 55 \\
\hline
\end{tabular}

\subsection{SEM / EDX results}

The initial observations of the samples' morphology were made via scanning electron microscopy, while bismuth content was quantified using EDX. Compositional properties of the samples are summarised in the Table 1, while selected SEM images are given in Figure 2. It is clear from the images that PC500-based samples were composed of much finer particles, compared to P25-based samples. Despite the fact that, in the given figure, we compare the SEM images of the uncoated samples with those for the samples with the highest bismuth oxide content (namely, PC500Bi60 
(Figure 2b) and P25Bi60 (Figure 2d)), no observable difference could be seen on the SEM images of coated and uncoated particles.
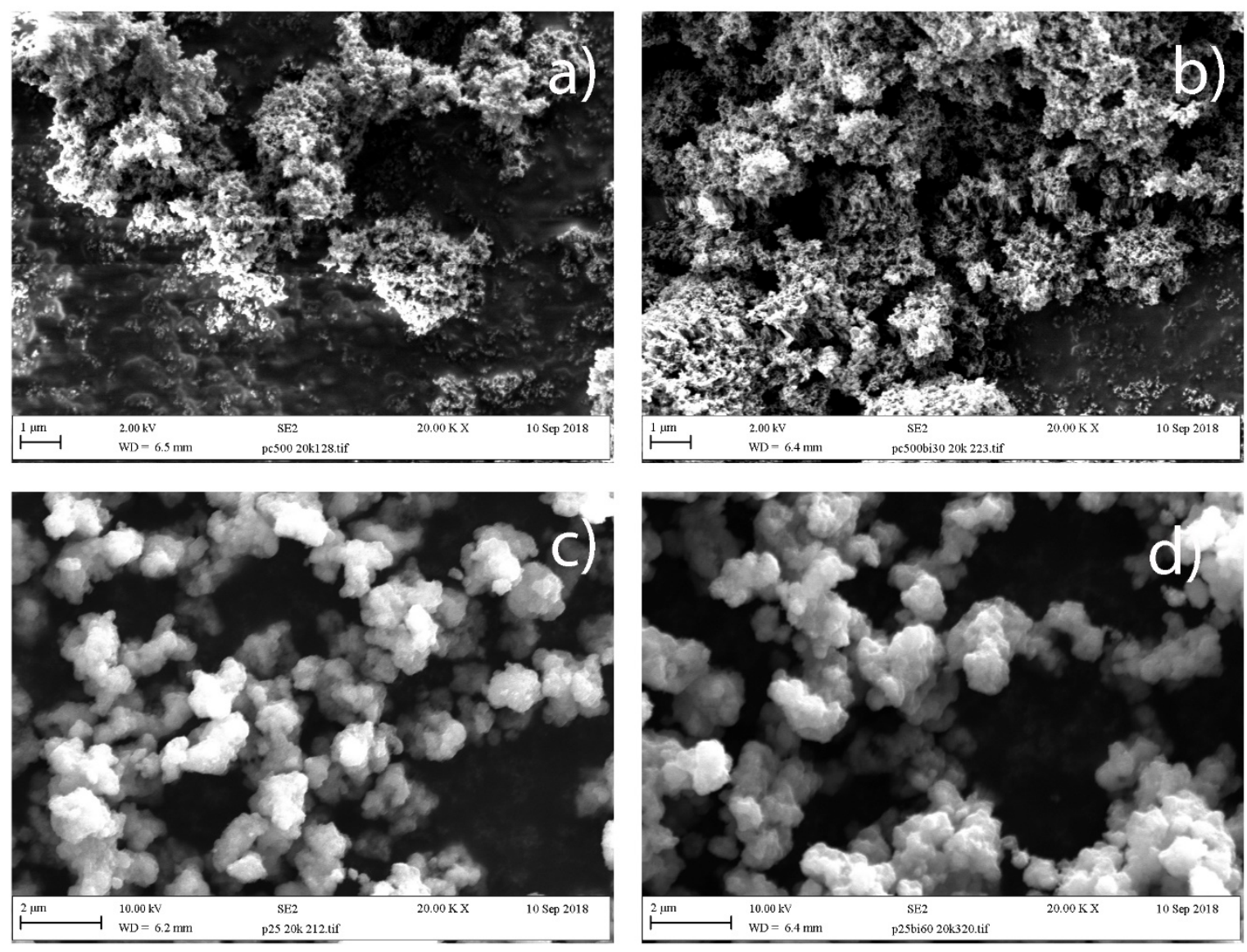

Figure 2. SEM images of selected coated and uncoated titania powders: a) sample PC500; b) sample PC500Bi60; c) sample P25; d) sample P25Bi60

\subsection{Brunauer-Emmett-Teller (BET) specific surface area}

The specific surface area values of the samples were determined by $\mathrm{N}_{2}$ adsorption/desorption using the Brunauer-Emmett-Teller (BET) method. The values obtained for surface area are summarised in Table 1. As expected, PC500-based samples were characterised with much higher values of the surface area, compared to P25-based titania samples. It can be seen that the measured surface areas were in good correlation with the literature information for either type of substrate used, 
where the surface are of PC500 is typically referred to $305-350 \mathrm{~m}^{2} \mathrm{~g}^{-1}[44,45]$, while for P25 a value of $56 \mathrm{~m}^{2} \mathrm{~g}^{-1}$ is frequently reported [46].

Interestingly, deposition of bismuth oxide had a different effect on the surface area values, depending on the type of titania substrate used. Thus, for the PC500-based array, deposition of bismuth oxide resulted in lower BET area values, from $325 \mathrm{~m}^{2} \mathrm{~g}^{-1}$ for uncoated particles to $297 \mathrm{~m}^{2} \mathrm{~g}^{-1}$ for sample PC500Bi60. Such a reduction of the surface area is typically reported to be due to particle agglomeration in the process of movement in the oscillating bowl [38]. On the contrary, deposition of bismuth oxide had the opposite effect on the BET area values of the P25-based array of samples: longer bismuth oxide deposition times resulted in higher surface area values, except for sample P25Bi60, which exhibited a lower surface area than P25Bi15 and P25Bi30.

\subsection{XRD results}

The XRD patterns of unmodified and bismuth oxide-coated samples are presented in Figure 3; for ease of comparison, the data has been divided into two parts, based on the type of titanium dioxide nanoparticles used. For PC500-based samples (left), the peaks can be indexed to anatase titanium dioxide (crystallographic card number $96-900-8215$ ), with major peaks observed at $25.3^{\circ}, 37.8^{\circ}$, $48.0^{\circ}, 53.9^{\circ}, 55.0^{\circ}, 62.7^{\circ}, 68.8^{\circ}, 70.3^{\circ}$ and $75.0^{\circ}$. For samples PC500Bi30 and PC500Bi60 additional peaks can be seen at $27.9^{\circ}, 32.7^{\circ}$ and $46.2^{\circ}$ (the latter two were observed only for sample PC500Bi60); these peaks were identified as belonging to the tetragonal ( $\beta$ ) phase of bismuth oxide $\left(\mathrm{Bi}_{2} \mathrm{O}_{3}\right)$, according to the crystallographic card 96-901-2328.

In good accordance with the literature information, the XRD patterns of P25-based samples (right), showed a mixture of anatase and rutile peaks. While the positions of the anatase peaks were identical to those given above, additional rutile peaks were observed at $27.4^{\circ}, 36.0^{\circ}, 41.2^{\circ}, 54.3^{\circ}$, $56.6^{\circ}$ and $69.0^{\circ}$ (crystallographic card 96-901-5663). Similarly to the PC500-based array of samples, additional peaks were found on the XRD patterns for all bismuth oxide-modified titania samples at 
$32.7^{\circ}$ and $46.2^{\circ}$; the intensity of the peaks increased with increased deposition time. Interestingly, only the tetragonal phase bismuth oxide was found, regardless of the titanium dioxide used as the substrate. Also, it should be noted here that bismuth oxide was deposited in crystalline form without any further thermal treatment applied to the samples.
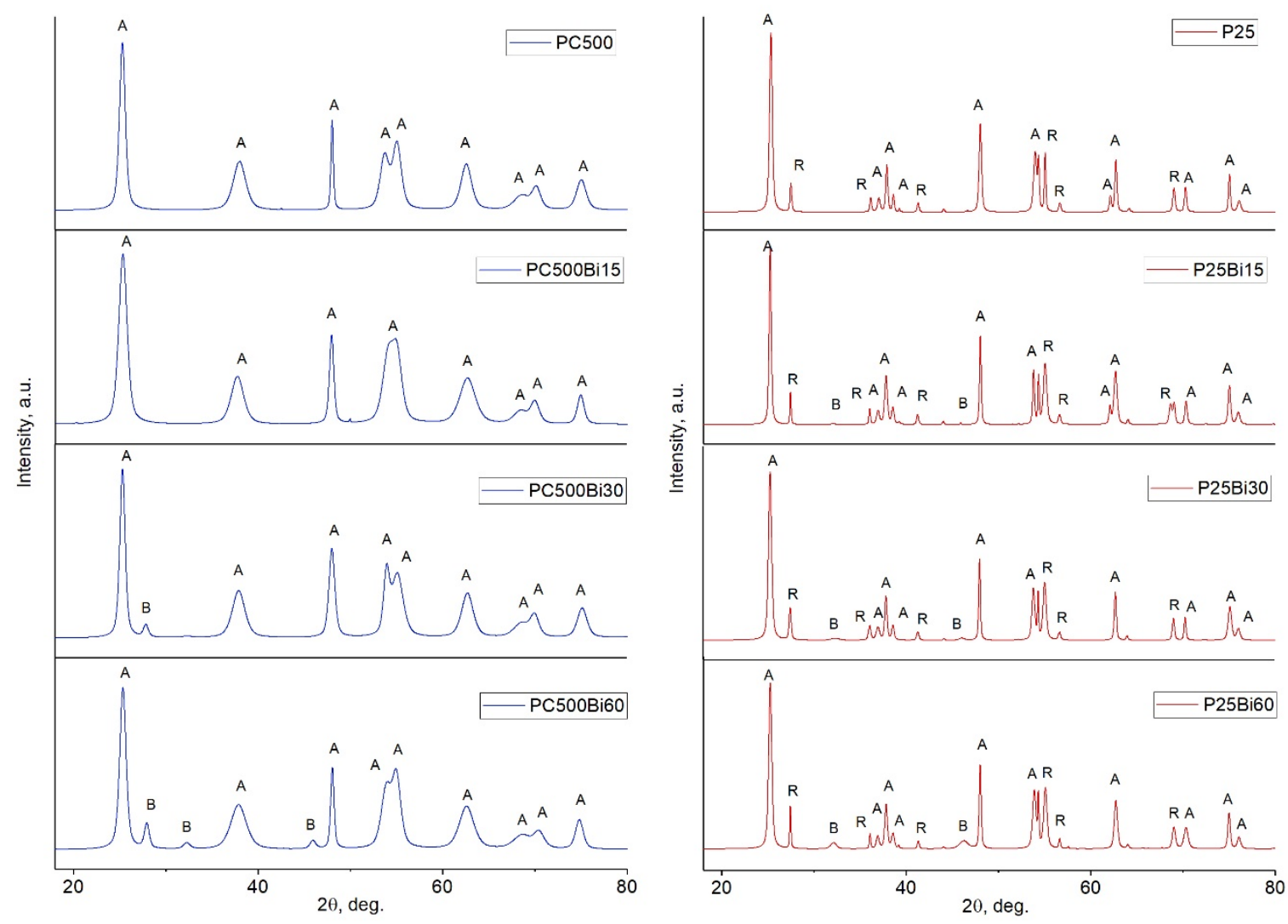

Figure 3. XRD patterns of bismuth oxide-coated and uncoated titanium dioxide samples ( $A$-anatase; $R$-rutile; $B$-bismuth oxide)

3.4.XPS results 

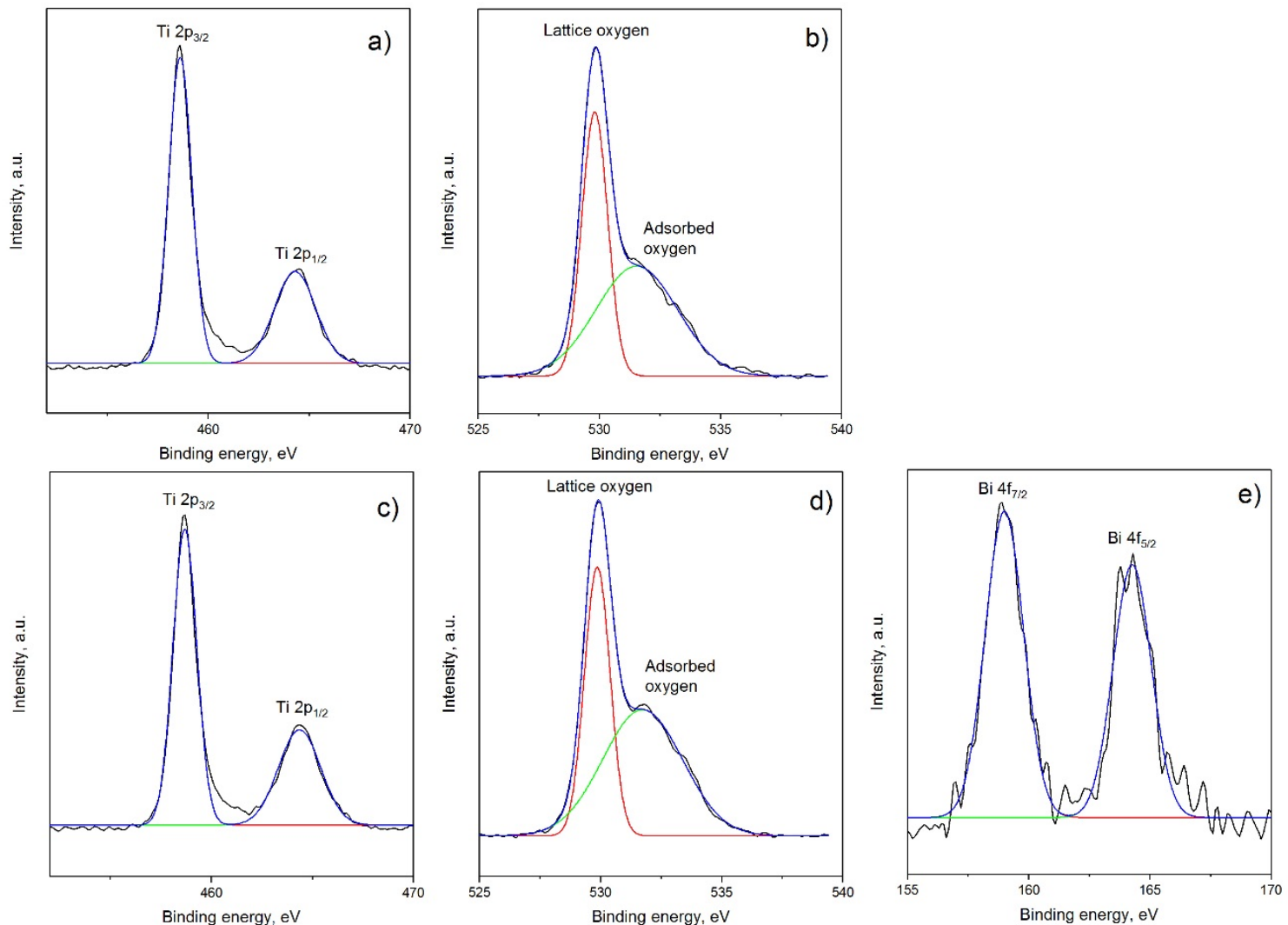

Figure 4. High resolution XPS spectra of PC500-based samples: a) Ti 2p spectrum of sample PC500; b) O 1s spectrum of sample PC500; c) Ti 2p spectrum of sample PC500Bi30; d) O 1s spectrum of sample PC500Bi30; e) Bi $4 f$ spectrum of sample PC500Bi30 

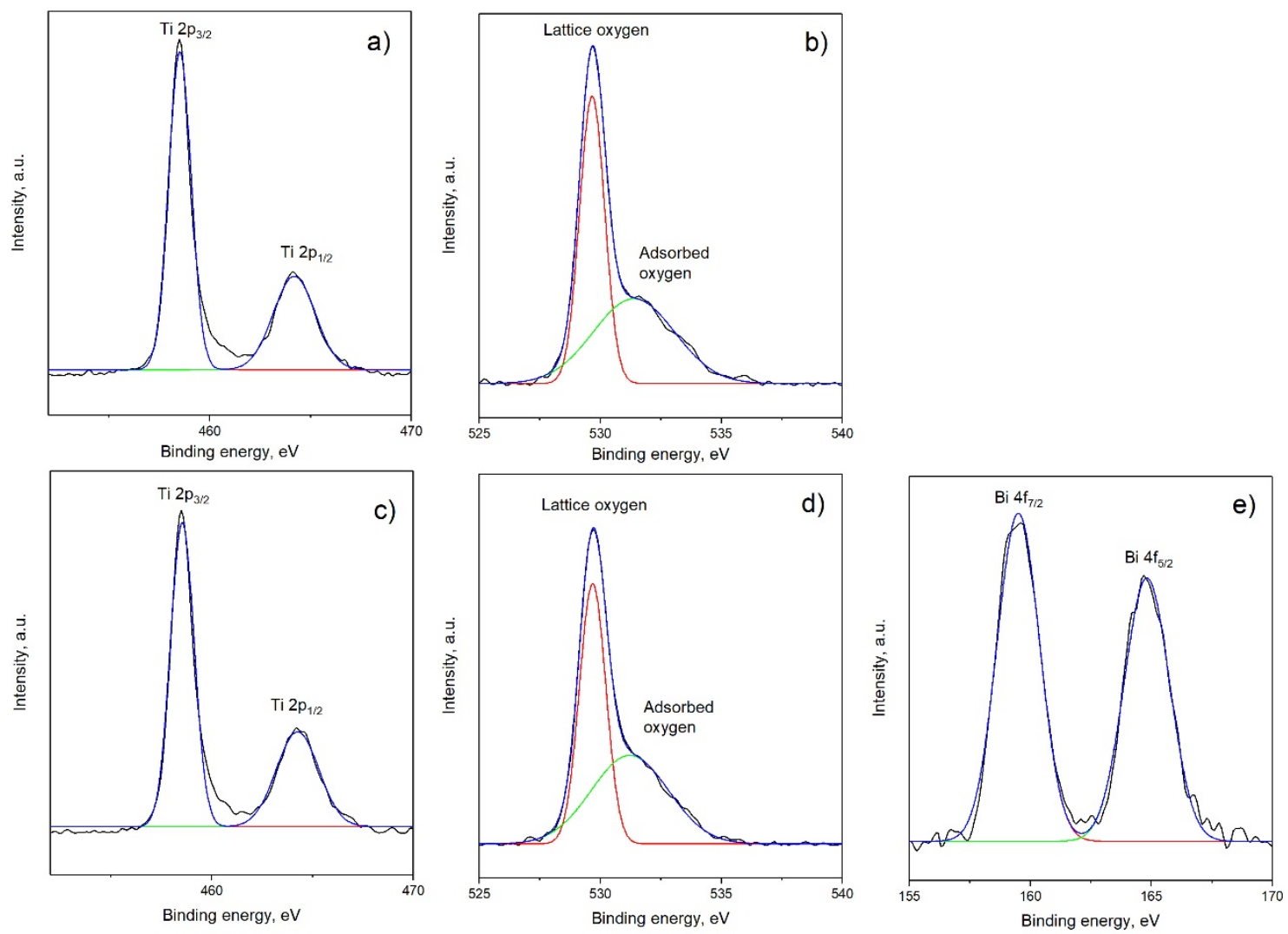

Figure 5. High resolution XPS spectra of P25-based samples: a) Ti 2p spectrum of sample P25; b) $O$ 1s spectrum of sample P25; c) Ti 2p spectrum of sample P25Bi30; d) O 1s spectrum of sample P25Bi30; e) Bi 4 f spectrum of sample P25Bi30

The XPS analysis was carried out to investigate the oxidation state of the elements; Gaussian functions were used for deconvolution of the individual peaks. According to the survey spectra (not given here), uncoated titania samples showed only Ti $2 p, 01 s$ and $C 1 s$ peaks (the latter one is due to adventitious carbon on the surface; the binding energies of the other elements were referenced to this peak at $284.8 \mathrm{eV}$ ), while on the spectra of the coated samples the B $4 \mathrm{f}$ peak can be clearly observed in all cases. Examples of high-resolution XPS spectra of the uncoated sample, compared to the bismuth oxide-coated sample for PC500 and P25 substrates are shown in Figures 4 and 5, respectively. Clearly, for Ti $2 p$ and 0 1s peaks, no shift was observed for either of the substrates used, indicating that bismuth oxide is present in each case as a separate phase and not incorporated into the titania lattice. Thus, for Ti $2 p$, two peaks corresponding to Ti $2 p_{3 / 2}$ and Ti $2 p_{1 / 2}$ can be seen at 458.5 and $464.2 \mathrm{eV}$, respectively. The oxygen peak can be deconvoluted in all cases into two peaks at 
529.6 and $531.5 \mathrm{eV}$, assigned typically to the lattice oxygen of $\mathrm{TiO}_{2}$ and $\mathrm{B}_{2} \mathrm{O}_{3}$ and surface adsorbed oxygen, respectively [33]. The high resolution spectrum of Bi $4 \mathrm{f}$ shows two peaks at 158.9 and 164.3 $\mathrm{eV}$ that can be assigned to the binding energies of $\mathrm{Bi} 4 \mathrm{f}_{7 / 2}$ and $\mathrm{Bi} 4 \mathrm{f}_{5 / 2}$ states, in good agreement with the literature information $[28,33]$. As evidenced by earlier studies of bismuth oxide / titanium dioxide nanocomposites, the absence of the $\mathrm{Bi} 4 \mathrm{f}_{7 / 2}$ peaks at binding energies over $159 \mathrm{eV}$ is indicative of $\mathrm{Bi}(\mathrm{III})$ present in an oxide chemical state $[28,47]$. Also, the absence of the minor peaks next to the main peaks is typically explained by the absence of the oxygen-deficient bismuth oxide phases, therefore, in our case, in accordance with the XRD information, stoichiometric $\beta$-bismuth oxide was deposited.

\subsection{TEM results}

In order to further investigate structural, phase and compositional properties of the prepared samples, TEM and HRTEM analysis was performed. Selected HRTEM results are presented in Figure 6. As expected, HRTEM of uncoated PC500 (Figure 6a) titania revealed small nanoparticles, ranging from 5 to $12 \mathrm{~nm}$ in size, in accordance with the literature information [44]. Crystal planes identified from selected area diffraction pattern (SAED) (examples are given in Supplementary material, Figure S1) were in good agreement with the XRD data discussed earlier and corresponded to anatase titanium dioxide only. HRTEM images of PC500 coated with bismuth oxide for 30 and 60 minutes are given in Figures $6 b$ and $6 c$, respectively. It can be seen that bismuth oxide was observed in the form of continuous sheets on top of the titania nanoparticles; the thickness of the sheet appeared to be increasing for longer deposition times. Corresponding selected area diffraction patterns are indicative of the polycrystalline structure of the coated samples, matching the plane reflections of both anatase titania and $\beta$-bismuth oxide.

HRTEM data for selected P25-based samples are shown in Figures 6d-f. Uncoated P25 titanium dioxide (Figure 6d), in accordance with supplier specifications, had particle sizes of 20-30 nm, with a diffraction pattern corresponding to a mixture of anatase and rutile $\mathrm{TiO}_{2}$. Interestingly, the 
distribution of bismuth oxide in the case of the P25-based array was clearly different from the PC500 samples. HRTEM images of samples P25Bi30 and P25Bi60 are shown in Figures $6 e$ and $6 \mathrm{f}$, respectively. It can be seen that, for 30 min deposition time, bismuth oxide forms small "clusters" on the surface of titanium dioxide particles. As deposition time increases, the clusters coalesce and the bismuth oxide starts forming continuous coatings around the titania P25 nanoparticles. It should be noted, that according to the selected area diffraction patterns, the substrate did not affect the bismuth oxide phase, and for the P25 substrates, bismuth oxide was still found in tetragonal $\beta$ phase, in good agreement with the XRD data. The results obtained for both sample arrays were also in good agreement with the surface area information discussed earlier. Thus, for P25-based samples formation of small "clusters" in the surface of the titania nanoparticles (deposition times of 15 and $30 \mathrm{~min}$ ) resulted in increased surface area values, compared to an uncoated substrate; however, further increase of deposition time resulted in formation of continuous coating on the titania nanoparticles and, consequently, a lower surface area for sample P25Bi60.

For further verification of the bismuth oxide distribution on the two types of titanium dioxide substrate used, HAADF-STEM imaging and EDS elemental mapping have been performed on all composite samples. Elemental distributions of bismuth on titanium dioxide confirmed the initial TEM findings. An example of HAADF imaging and elemental distribution for sample P25Bi60 is shown in Figure 7. From the distribution of bismuth on the surface of the titania nanoparticles, it can be seen that, as observed earlier with HRTEM, for $\mathrm{P} 25 \mathrm{TiO}_{2}$, bismuth oxide formed a coating around the nanoparticles, while for the PC500 array it existed rather in the form of sheets. As found earlier [10, $42,48]$, for magnetron sputtered films deposited onto particulates, this distribution difference is due to the difference in the dynamics of the movement of the substrate particulates in the oscillating bowl during deposition, where larger particulates are more likely be more uniformly coated. 

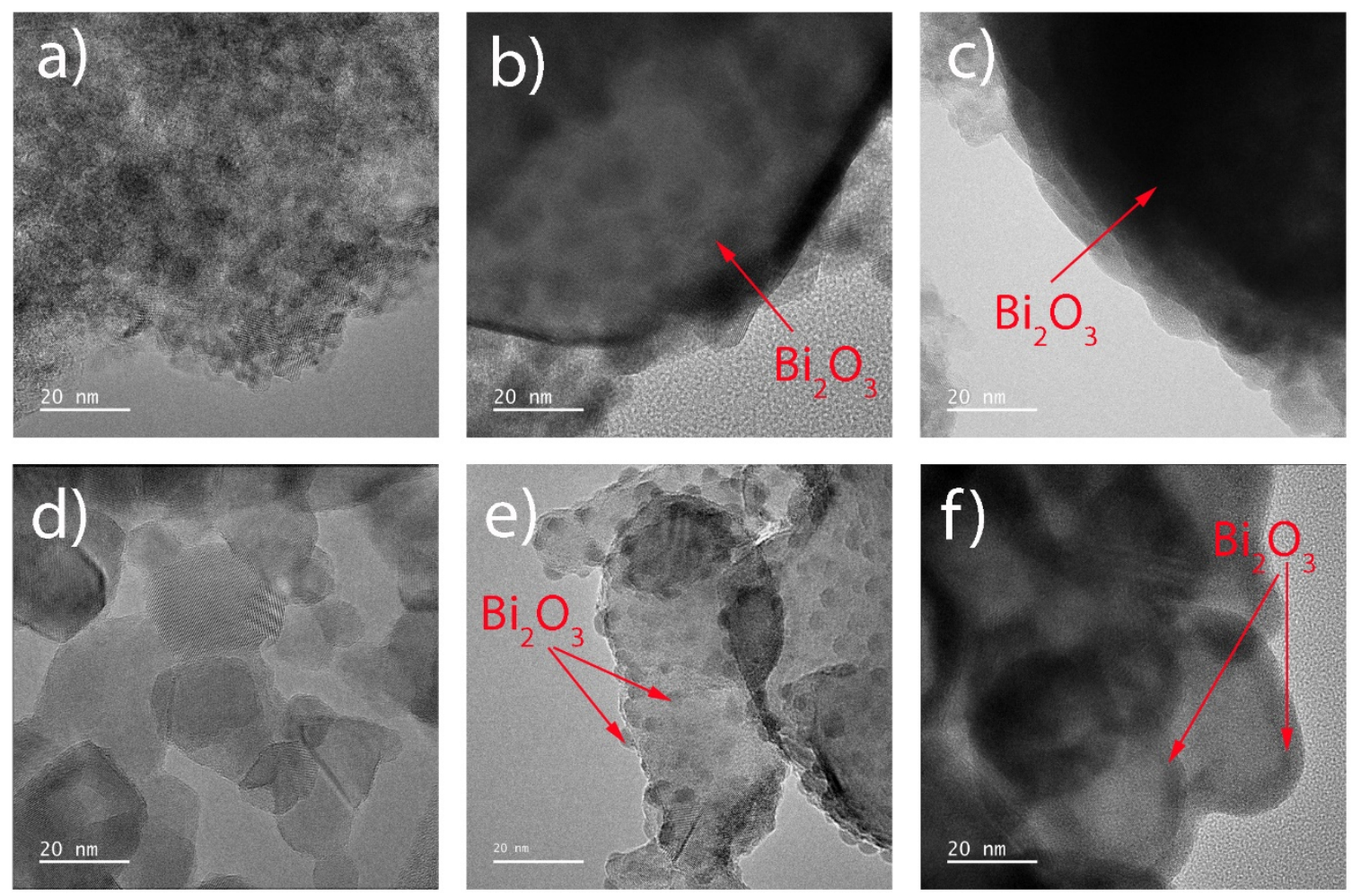

Figure 6. HRTEM images of uncoated and bismuth oxide-coated titania samples: a) sample PC500; b) sample PC500Bi30; c) PC500Bi60; d) sample P25; e) sample P25Bi60; f) sample P25Bi60 

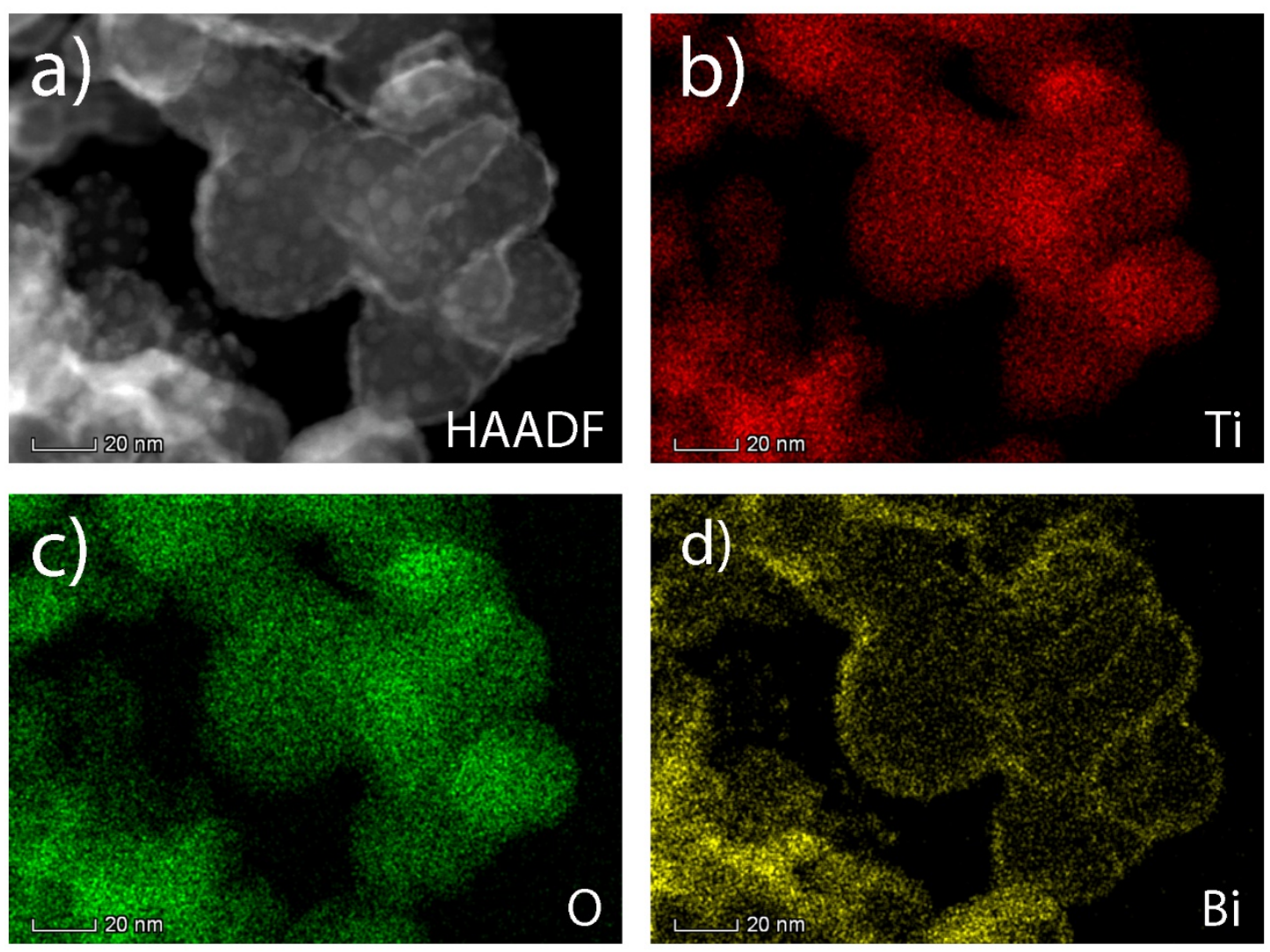

Figure 7. Example of HAADF-STEM-EDS maps of sample P25Bi60: a) HAADF-STEM image; b) Ti mapping; c) O mapping; d) Bi

mapping

3.6. Band gap calculation (UV-vis diffuse reflectance spectroscopy)

Table 2. Summary of optical properties and photocatalytic test results

\begin{tabular}{|c|c|c|c|c|}
\hline Sample ID & Band gap, eV & $\begin{array}{l}\text { Wavelength of } \\
\text { light required for } \\
\text { photoactivation, } \\
\mathrm{nm}\end{array}$ & $\begin{array}{l}\text { Amount of } \mathrm{CO}_{2} \\
\text { produced during } \\
\text { 1h of acetone } \\
\text { degradation } \\
\text { under visible } \\
\text { light, ppm }\end{array}$ & $\begin{array}{l}\text { Amount of } \mathrm{CO}_{2} \\
\text { produced during } \\
\text { 1h of methanol } \\
\text { degradation } \\
\text { under visible } \\
\text { light, ppm }\end{array}$ \\
\hline PC500 & 3.23 & 383.9 & 10 & 10 \\
\hline PC500Bi15 & 3.20 & 387.5 & 160 & 110 \\
\hline
\end{tabular}




\begin{tabular}{|l|l|l|l|l|}
\hline PC500Bi30 & 3.18 & 389.9 & 400 & 330 \\
\hline PC500Bi60 & 3.16 & 392.4 & 570 & 480 \\
\hline P25 & 3.08 & 402.6 & 20 & 20 \\
\hline P25Bi15 & 3.00 & 413.3 & 330 & 260 \\
\hline P25Bi30 & 2.97 & 417.5 & 490 & 420 \\
\hline P25Bi60 & 2.91 & 426.1 & 440 & 390 \\
\hline
\end{tabular}

As the optical properties of photocatalytic materials and their photon absorption capabilities, in particular, are directly related to their photocatalytic behaviour under light of particular wavelengths, UV-vis DRS studies were performed to investigate what effect the deposition of bismuth oxide had on the optical properties of nanoparticulate titania.

The band gap energies of the samples were determined by plotting $(F(R) h v)^{1 / 2}$ vs hv and extrapolating the linear region of the plot to the abscissa. The plots are presented in the Figure 8. The band gap energy values obtained and the wavelengths required for photoactivation of the samples are summarised in Table 2, as well as information on the minimum light wavelengths required for photoactivation. As the band gap of magnetron-sputtered bismuth oxide is reported to be in the range of $2.4 \mathrm{eV}[10,19]$, deposition of it onto titania nanoparticles was expected to narrow the band gap and, therefore, improve visible light absorption. Indeed, all bismuth oxide-coated samples exhibited a red shift of the absorption edge, compared to uncoated titania. Not surprisingly, the P25-based array of samples was characterised with lower band gap values, owing both to the lower band gap of the uncoated substrate, due to it consisting of a mixture of anatase and rutile (3.08 eV - in good agreement with literature information where the band gap of pristine P25 titanium dioxide is typically reported to be in the range of $3.10 \mathrm{eV}$ [49]), and contained a higher amount of deposited bismuth oxide, compared to the PC500-based array. Thus, the band gap 
narrowing for samples with the highest amount of deposited bismuth oxide were 0.07 and $0.17 \mathrm{eV}$ for samples PC500Bi60 and P25Bi60, respectively.
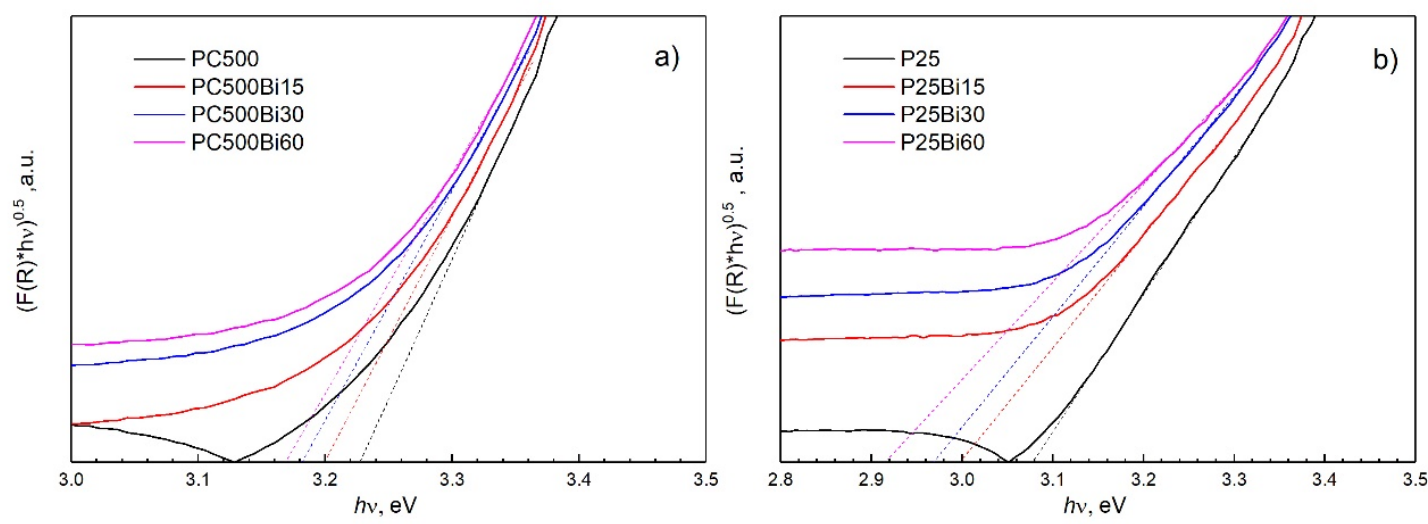

Figure 8. Band gap calculation using Kubelka-Munk function: a) PC500-based samples; b) P25-based samples

\subsection{Photocatalytic activity assessment}

Photocatalytic properties of the samples were assessed based on their ability to degrade acetone and methanol - both are common pollutants (referred to as volatile organic compounds; VOCs) frequently used for evaluation of photocatalytic activity. The selected model pollutants are frequently reported as harmful agents in many industrial applications that can be easily mineralised without the formation of gaseous intermediates [50-53]. Moreover, both model pollutants only absorb UV light [50], and are therefore unlikely to be affected by visible light irradiation. Indeed, a series of blank tests performed $\left(\mathrm{CO}_{2}\right.$ evolution measurements for each pollutant with no sample in the reaction cell under visible light irradiation) confirmed the stability of the selected VOCs. It should be noted here that the aim of the study was not to compare the photocatalytic performance of two commercially available titania catalysts, but rather evaluate the effect of bismuth-oxide deposition on the photocatalytic properties of titania nanoparticles under visible-light irradiation.

The results of carbon dioxide evolution during 1 hour of visible light irradiation for all studied samples are presented in Figure 9. It is clear that no appreciable $\mathrm{CO}_{2}$ evolution was observed for 
unmodified titania powders for either VOC used. In contrast, the presence of bismuth oxide deposited on the surface of the titania nanoparticles resulted in increased rates of carbon dioxide evolution for all samples studied; similar trends in $\mathrm{CO}_{2}$ evolution were observed for the degradation of both model pollutants over bismuth oxide-coated samples. Thus, for the PC500-based array of samples the photocatalytic activity under visible light decayed in the following order: PC500Bi60 > PC500Bi30 > PC500Bi15 > PC500, while for the P25 array it was P25Bi30 > P25Bi60 > P25Bi15 > P25. Despite similar trends in degradation for both model pollutants, slightly higher $\mathrm{CO}_{2}$ evolution rates were observed for acetone, compared to methanol.

It is a known fact that enhanced visible light photocatalytic activity may be originated from several factors (or combination of them), namely enhanced light absorption, longer lifetimes of photogenerated charge carriers and improved photon utilization efficiency [33]. Absence of photocatalytic activity under simulated visible light irradiation of pristine PC500 titanium dioxide was not surprising, given relatively high band gap value. However, interestingly, all PC500-based samples were still characterised with band gap values below the energy of the light used for the photocatalytic tests, nevertheless, there was appreciable $\mathrm{CO}_{2}$ evolution for all composite samples of the array. On the contrary, uncoated P25 titania has a band gap value above the energy of the simulated visible light used for the tests, however, there was no $\mathrm{CO}_{2}$ evolution registered for either of two pollutants used. Apparently, owing to the lower band gap value, of these two materials only bismuth oxide can be excited under visible light irradiation to generate electron-hole pairs. Therefore, it is clear that deposition of even a small amount of bismuth oxide resulted in improved visible light utilization. It is also frequently reported that bismuth oxide - titanium dioxide composite materials are characterised with more efficient electron transport charge separation rates, compared to pure titanium dioxide $[26,36]$. Notably, in our case the highest values of photocatalytic activity were observed for samples PC500Bi60 and P25Bi30 with very similar bismuth oxide contents (ca. 0.75 at.\% of $\mathrm{Bi}$, according to the EDX analysis). The fact that longer deposition time and, 
consequently, higher amount of bismuth oxide for sample P25Bi60 did not result in improved photocatalytic activity compared to P25Bi30, may be indicative of the fact that excessive amount of bismuth oxide may result in lower photocatalytic activity due to reduced charge carrier transfer rates on the bismuth oxide - titania interface [36]. In addition, lower photocatalytic activity of P25Bi60 may be also attributed to reduced surface area.
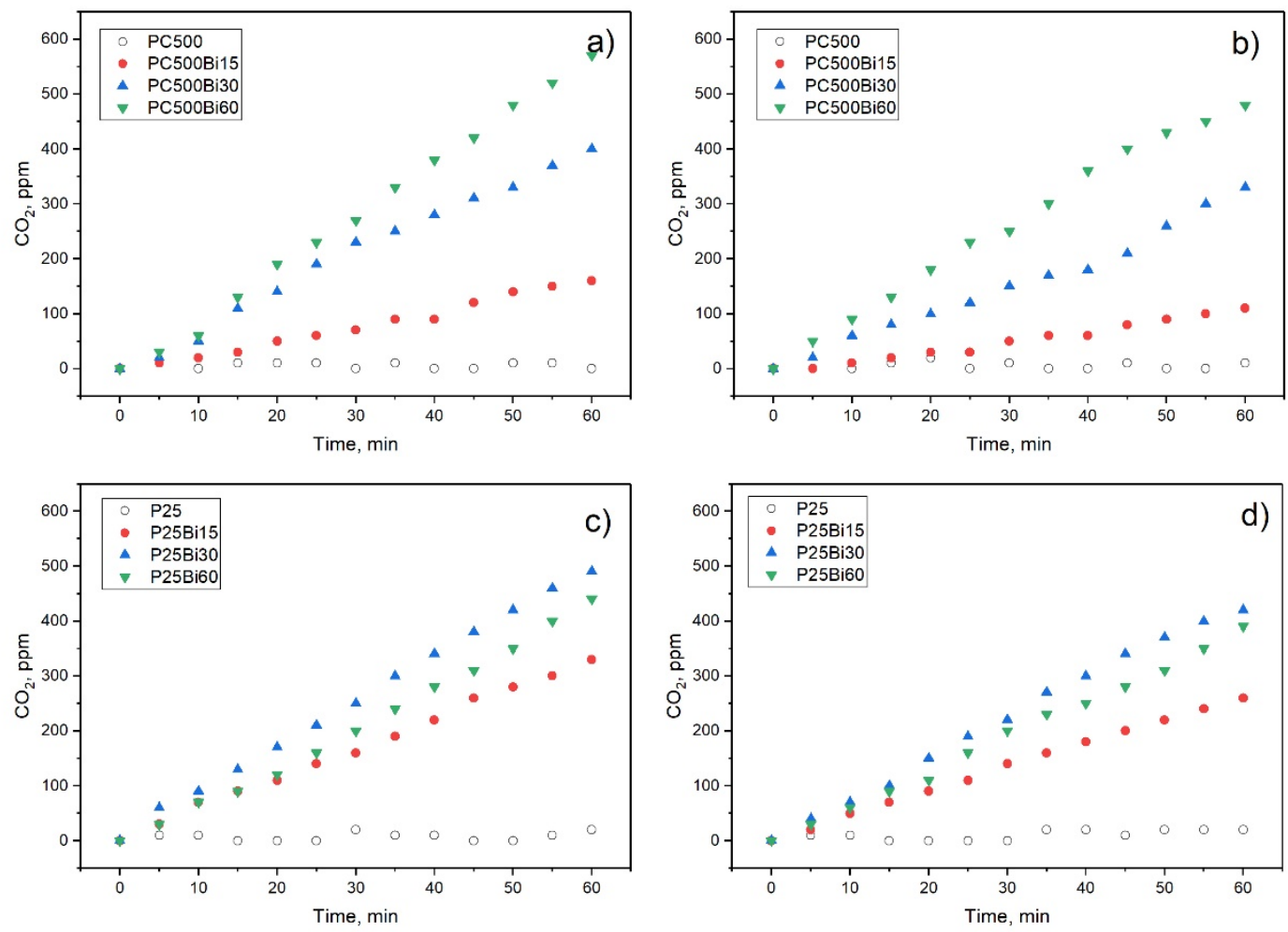

Figure 9. Results for photocatalytic $\mathrm{CO}_{2}$ evolution under visible light irradiation: a) acetone degradation by PC500-based samples; b) methanol degradation by PC500-based samples; c) acetone degradation by P25-based samples; d) methanol degradation by P25-based samples

\subsection{Photocatalytic repeatability experiments}

It is a well-known fact that the stability and reusability of photocatalysts are factors of key importance for their practical applicability. Therefore, a series of repeated experiments was performed to investigate reusability of the prepared bismuth oxide - titanium dioxide composite materials. The reusability tests were carried out with the best-performing sample of each array; 
namely PC500Bi60 and P25Bi30. Acetone degradation was performed under the same experimental conditions as outlined in Section 2.3 - Photocatalytic activity assessment. The results of repeated tests are illustrated in Figure 10. As can be seen, there was no significant loss of photocatalytic activity after 5 repeat cycles for either of the composite samples tested. Though the initial results do look encouraging, the stability of the composite photocatalysts should be confirmed under variable and harsher conditions to ensure durability for industrial applications - these tests are scheduled as a part of the follow-up work.

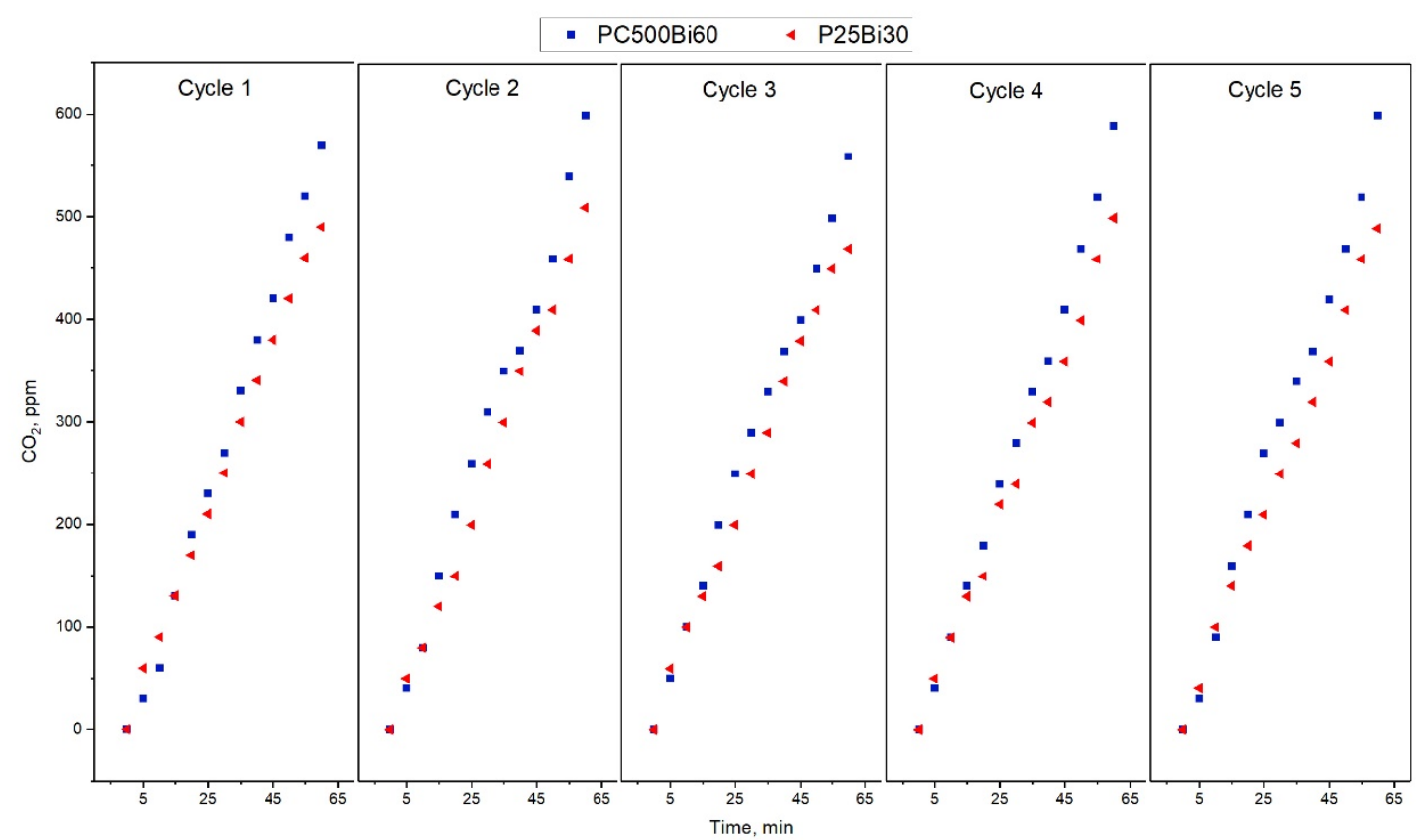

Figure 10. Example of $\mathrm{CO}_{2}$ evolution during 5 cycles of acetone degradation over samples PC500Bi60 and P25Bi30 under visible light irradiation 


\subsection{RDB-PAS results}
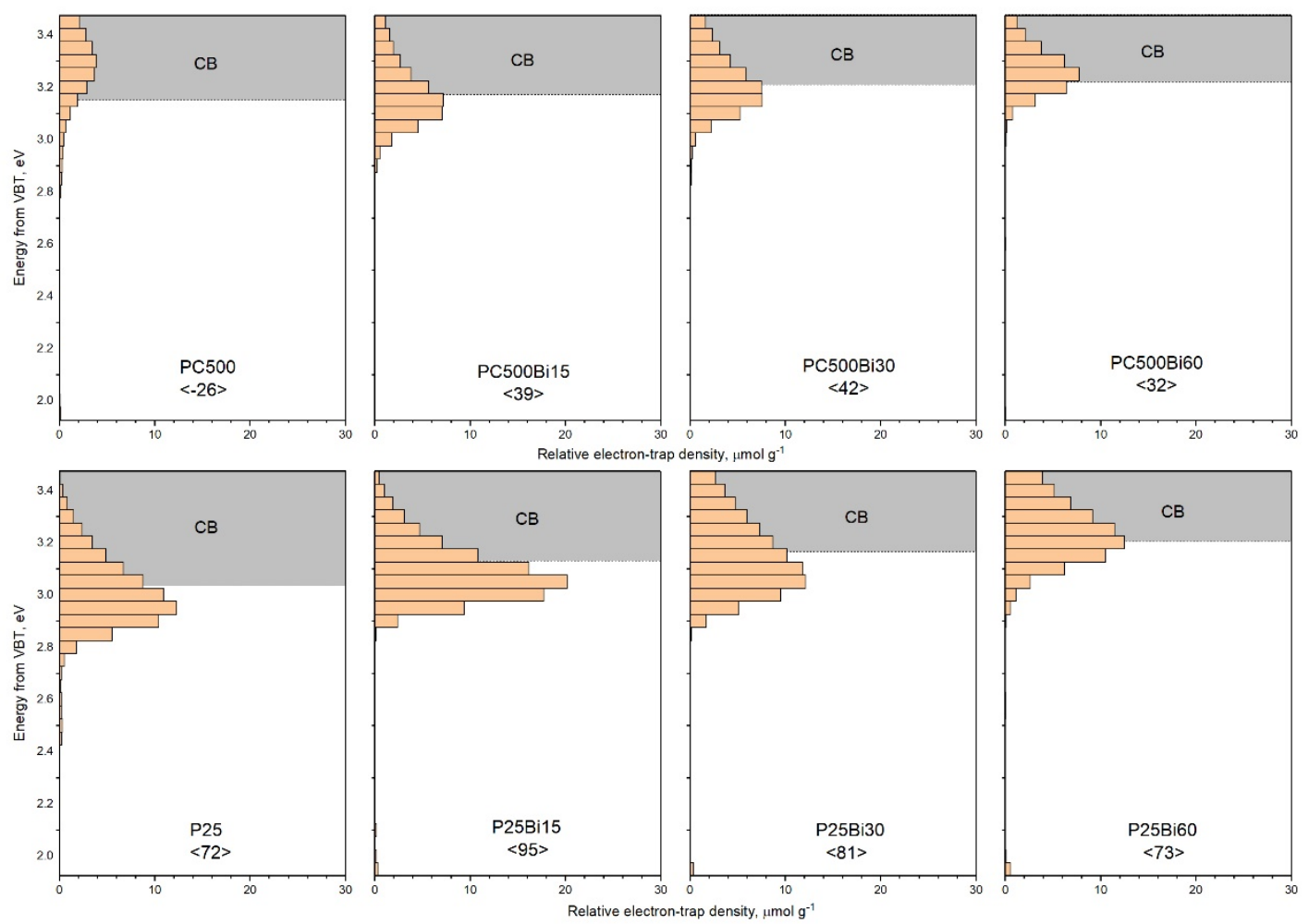

Figure 11. ERDT/CBB patterns of coated and uncoated titania powders. Figures in < > represent total density of electron traps in $\mu \mathrm{mol} \mathrm{g}^{-1}$

Figure 11 shows the patterns of energy-resolved distribution of electron traps combined with conduction-band-bottom position (ERDT/CBB) patterns of samples measured by RDB-PAS. The $x$ axis shows electron-trap density of each bar in $\mu \mathrm{mol} \mathrm{g}^{-1}$ on the assumption that all the electron traps are located on the titania surface [54], since, at this stage, no information on the nature and structure of those electron traps has been obtained, and therefore those values are "relative". The conduction band-bottom (CBB) position was calculated from the absorption-edge wavelength in an ordinary PA spectra as an energy difference from the valence-band top as same as the ERDT patterns. In this CBB-position estimation, a shoulder, often seen for composites, was neglected and thereby the values of the energy of the CBB corresponding to the bandgap are higher than those listed earlier in Table 2. For uncoated samples, PC500 and P25, the degree of coincidence of the 
ERDT pattern shape ( (la)) with commercially available titania samples was calculated using reported data [55], and the results showed that PC500 resembles Ishihara Sangyo ST-01 ( $\zeta(a)=0.83)$ and its equivalent powders (Catalysis Society of Japan, JRC-TIO-8 $(\zeta(a)=0.79)$ and JRC-TIO-14 $(\zeta(a)=0.79)$ ) [55], while P25 resembles, of course, P25 $(\zeta(a)=0.84)$ and its equivalent powders (Catalysis Society of Japan, JRC-TIO-4 $(\zeta(\mathrm{a})=0.75)$ and JRC-TIO-15 $(\zeta(\mathrm{a})=0.80))$. It has been reported that ST-01 and its equivalent samples are characterised with lower crystallinity, i.e. they are composed of ca. $80 \%$ of anatase and $20 \%$ of non-crystalline components (amorphous titanium dioxide and/or water) with high specific surface area $>300 \mathrm{~m}^{2} \mathrm{~g}^{-1}$. The above-mentioned high degree of coincidence of the ERDT patterns suggests that PC500 is also small-sized anatase titania with relatively large amount of non-crystalline components, which is in good agreement with relatively broad XRD peaks shown in Figure 3. The observed relatively high, ca. $3.3 \mathrm{eV}$, ERDT-peak position and relatively low total electron-trap density have been commonly observed for anatase/amorphous titania samples. On the other hand, P25 is a mixture of anatase and rutile (with small amount of non-crystalline components) with relatively large crystallite size as confirmed by the sharper XRD peaks depicted in the Figure 3.

Coating of those samples with bismuth oxide induced appreciable change in the shapes of the ERDT/CBB patterns. Thus, for PC500, the ERDT peak was shifted to the lower-energy side by a 15min coating and then to higher-energy side by the longer deposition times of 30 and $60 \mathrm{~min}$. Compared with an ERDT pattern of a commercial bismuth-oxide $\left(\mathrm{Bi}_{2} \mathrm{O}_{3}\right)$ sample (Wako) (the pattern is given in the Figure S2 - Supplementary material), the ERDT pattern of PC500-BiO60 exhibited a peak energy similar to that of commercial $\mathrm{Bi}_{2} \mathrm{O}_{3}$. On the other hand, ERDT patterns of coated P25 samples were shifted to the higher-energy side as the deposition time increased, without showing a lower-energy shift at a shorter coating time, to give a pattern similar to that of commercial $\mathrm{Bi}_{2} \mathrm{O}_{3}$. Assuming that coverage of the titania surfaces for both types of substrate increased gradually with an increase of the deposition time from 15 to $60 \mathrm{~min}$, ERDT patterns of composite samples are 
mainly composed of the ERDT of bismuth oxide. It was observed for P25-based samples that the CBB position was gradually increased with coating time. Since P25 contains a small amount (ca. 15\%) of rutile of a slightly smaller band gap, compared with that of anatase, a longer-wavelength absorption by rutile in P25 might disappear due to the bismuth-oxide coating to shift the CBB towards the higher-energy side (anatase CBB). The lower energy-side shift of ERDT for PC500-BiO15 might be due to removal of water or surface hydroxyls, which are expected to exist appreciably on PC500 as suggested by the similarity with ST-01, during the bismuth-oxide deposition process, since ST-01 showed a similar ERDT-pattern shift upon evacuation at ca. 393K [56]. Differently from P25, PC500 has relatively high specific surface area and therefore the original titania surface may be still exposed after a short-time bismuth-oxide coating, which might induce the lower energy-ERDT shift of PC500-BiO15. Also, according to the EDX results the overall amount of bismuth oxide was lower for PC500-based array of samples, which may be another reason for not seeing shifts of the ERDT patterns to the higher energy side, as in the case of P25-based composite samples.

\section{Conclusions}

In summary, the work has demonstrated the effectiveness of the method of production of efficient visible light photocatalysts based on the one-step deposition of bismuth oxide onto commercially available titania nanoparticles (namely, PC500 and P25) using reactive magnetron sputtering. The introduction of the oscillating bowl mechanism enabled deposition of bismuth oxide coatings onto titanium dioxide nanoparticulates; the deposited material was in crystalline form without any additional heat treatment applied - tetragonal $(\beta)$ phase of bismuth oxide $\left(\mathrm{Bi}_{2} \mathrm{O}_{3}\right)$ for either of two types of substrates used. The amount of bismuth oxide was controlled via variation of the deposition time. It was found that the morphology of the deposited bismuth oxide depends greatly on the titania particle size, where for smaller nanoparticles (PC500) it was found in "sheets", while for larger titania particles (P25) it initially formed small clusters on the particle surface, and continuous coating as the deposition time increased. Both types of composite materials were characterised with 
narrower band gap values, compared to uncoated titania, and exhibited notably higher

photocatalytic response in the degradation of acetone and methanol under visible light irradiation.

Though due to the difference in surface area, no direct comparison of two types of composite

materials was performed, in both case the best results for either of the two model pollutants were

obtained for the sample with ca. 0.75 at.\% of Bi. Overall, we believe that the deposition of bismuth

oxide by magnetron sputtering may be an efficient method of introducing visible light activity to

commercial titanium dioxide photocatalysts. Further studies, including the precise determination of

the optimum $\mathrm{Bi}_{2} \mathrm{O}_{3}$ concentration, as well as applicability of the composite materials for degradation

of the other environmentally-relevant pollutants, are currently in progress.

\section{Acknowledgement}

The authors thank Dr. Akio Nitta for his help in RDB-PAS analyses and Ms. Miki Sasaki for her effort for degree of coincidence analysis with commercial titania samples.

\section{References}

[1] A. Fujishima, K. Honda, S. Kikuchi, Photosensitized electrolytic oxidation on semiconducting ntype TiO2 electrode, Kogyo Kagaku Zasshi 72 (1969) 108-113.

[2] S. Rehman, R. Ullah, A.M. Butt, N.D. Gohar, Strategies of making TiO2 and ZnO visible light active, Journal of Hazardous Materials 170(2-3) (2009) 560-569.

[3] A. Fujishima, X. Zhang, Titanium dioxide photocatalysis: present situation and future approaches, Comptes Rendus Chimie 9(5-6) (2006) 750-760.

[4] P. Pichat, Photocatalysis. Fundamentals, Materials and Potential, MDPI Books (2016).

[5] J.C. Colmenares, Y.-J. Xu, Heterogeneous Photocatalysis. From Fundamentals to Green Applications, Springer (2016).

[6] M.A. Henderson, A surface science perspective on TiO2 photocatalysis, Surface Science Reports 66(6) (2011) 185-297.

[7] H. Yu, J. Li, Y. Zhang, S. Yang, K. Han, F. Dong, T. Ma, H. Huang, Three-in-One Oxygen Vacancies: Whole Visible-Spectrum Absorption, Efficient Charge Separation, and Surface Site Activation for Robust CO2 Photoreduction, Angewandte Chemie International Edition 58(12) (2019) 3880-3884. [8] F. Chen, H. Huang, L. Guo, Y. Zhang, T. Ma, The role of polarization in photocatalysis, Angewandte Chemie International Edition, in press (2019).

[9] H. Huang, S. Tu, C. Zeng, T. Zhang, A.H. Reshak, Y. Zhang, Macroscopic Polarization Enhancement Promoting Photo- and Piezoelectric-Induced Charge Separation and Molecular Oxygen Activation, Angewandte Chemie International Edition 56(39) (2017) 11860-11864. 
[10] M. Ratova, R. Marcelino, P. de Souza, C. Amorim, P. Kelly, Reactive Magnetron Sputter Deposition of Bismuth Tungstate Coatings for Water Treatment Applications under Natural Sunlight, Catalysts 7(10) (2017) 283.

[11] M. Ratova, G.T. West, P.J. Kelly, Photocatalytic visible-light active bismuth tungstate coatings deposited by reactive magnetron sputtering, Vacuum 115(0) (2015) 66-69.

[12] F. Amano, K. Nogami, B. Ohtani, Enhanced photocatalytic activity of bismuth-tungsten mixed oxides for oxidative decomposition of acetaldehyde under visible light irradiation, Catalysis Communications 20(0) (2012) 12-16.

[13] M. Ratova, P. Kelly, G. West, X. Xia, Y. Gao, Deposition of Visible Light Active Photocatalytic Bismuth Molybdate Thin Films by Reactive Magnetron Sputtering, Materials 9(2) (2016) 67.

[14] A. Martínez-de la Cruz, L.G. Gracia Lozano, Photoassisted degradation of organic dyes by $\beta$ Bi2Mo2O9, Reaction Kinetics, Mechanisms and Catalysis 99(1) (2010) 209-215.

[15] J. Ren, W. Wang, M. Shang, S. Sun, E. Gao, Heterostructured Bismuth Molybdate Composite: Preparation and Improved Photocatalytic Activity under Visible-Light Irradiation, ACS Applied Materials \& Interfaces 3(7) (2011) 2529-2533.

[16] J. Hou, S. Jiao, H. Zhu, R.V. Kumar, Facile synthesis and visible-light photocatalytic activity of bismuth titanate nanorods, Journal of Nanoparticle Research 13(10) (2011) 5557-5564.

[17] C. Adán, J. Marugán, S. Obregón, G. Colón, Photocatalytic activity of bismuth vanadates under UV-A and visible light irradiation: Inactivation of Escherichia coli vs oxidation of methanol, Catalysis Today 240 (2015) 93-99.

[18] S. Kunduz, G.S. Pozan Soylu, Highly active BiVO4 nanoparticles: The enhanced photocatalytic properties under natural sunlight for removal of phenol from wastewater, Separation and Purification Technology 141 (2015) 221-228.

[19] M. Ratova, J. Redfern, J. Verran, P.J. Kelly, Highly efficient photocatalytic bismuth oxide coatings and their antimicrobial properties under visible light irradiation, Applied Catalysis B: Environmental 239 (2018) 223-232.

[20] B. Sirota, J. Reyes-Cuellar, P. Kohli, L. Wang, M.E. McCarroll, S.M. Aouadi, Bismuth oxide photocatalytic nanostructures produced by magnetron sputtering deposition, Thin Solid Films 520(19) (2012) 6118-6123.

[21] Y. Bessekhouad, D. Robert, J.V. Weber, Photocatalytic activity of Cu2O/TiO2, Bi2O3/TiO2 and ZnMn2O4/TiO2 heterojunctions, Catalysis Today 101(3) (2005) 315-321.

[22] P.Y. Ayekoe, D. Robert, D.L. Goné, Preparation of effective TiO2/Bi2O3 photocatalysts for water treatment, Environmental Chemistry Letters 14(3) (2016) 387-393.

[23] J. Chen, S. Qin, Y. Liu, F. Xin, X. Yin, Preparation of a visible light-driven Bi2O3-TiO2 composite photocatalyst by an ethylene glycol-assisted sol-gel method, and its photocatalytic properties, Research on Chemical Intermediates 40(2) (2014) 637-648.

[24] M. Malligavathy, S. Iyyapushpam, S.T. Nishanthi, D. Pathinettam Padiyan, Remarkable catalytic activity of Bi2O3/TiO2 nanocomposites prepared by hydrothermal method for the degradation of methyl orange, Journal of Nanoparticle Research 19(4) (2017) 144.

[25] Y. Huo, X. Chen, J. Zhang, G. Pan, J. Jia, H. Li, Ordered macroporous Bi2O3/TiO2 film coated on a rotating disk with enhanced photocatalytic activity under visible irradiation, Applied Catalysis B: Environmental 148-149 (2014) 550-556.

[26] L. Jing, J. Wang, Y. Qu, Y. Luan, Effects of surface-modification with Bi2O3 on the thermal stability and photoinduced charge property of nanocrystalline anatase $\mathrm{TiO} 2$ and its enhanced photocatalytic activity, Applied Surface Science 256(3) (2009) 657-663.

[27] A. Rahman, Y.C. Ching, K.Y. Ching, N. Awanis, A.K. Chakraborty, C.H. Chuah, N.-S. Liou, Surface Modification of Natural Fiber using Bi2O3/TiO2 Composite for Photocatalytic Self-cleaning, 2015.

[28] M.N. Gómez-Cerezo, M.J. Muñoz-Batista, D. Tudela, M. Fernández-García, A. Kubacka, Composite $\mathrm{Bi} 2 \mathrm{O} 3-\mathrm{TiO} 2$ catalysts for toluene photo-degradation: Ultraviolet and visible light performances, Applied Catalysis B: Environmental 156-157 (2014) 307-313. 
[29] D. Li, Y. Zhang, Y. Zhang, X. Zhou, S. Guo, Fabrication of bidirectionally doped $\beta$-Bi2O3/TiO2-NTs with enhanced photocatalysis under visible light irradiation, Journal of Hazardous Materials 258-259 (2013) 42-49.

[30] S. Sood, S.K. Mehta, A.S.K. Sinha, S.K. Kansal, Bi2O3/TiO2 heterostructures: Synthesis, characterization and their application in solar light mediated photocatalyzed degradation of an antibiotic, ofloxacin, Chemical Engineering Journal 290 (2016) 45-52.

[31] D. Sud, A. Syal, Investigations on the Phase Transformation, Optical Characteristics, and Photocatalytic Activity of Synthesized Heterostructured Nanoporous Bi2O3-TiO2, Journal of the Chinese Chemical Society 63(9) (2016) 776-783.

[32] P.Y. Ayekoe, D. Robert, D.L. Goné, TiO2/Bi2O3 photocatalysts for elimination of water contaminants. Part 1: synthesis of $\alpha$ - and $\beta$-Bi2O3 nanoparticles, Environmental Chemistry Letters 13(3) (2015) 327-332.

[33] N. Wei, H. Cui, C. Wang, G. Zhang, Q. Song, W. Sun, X. Song, M. Sun, J. Tian, Bi2O3 nanoparticles incorporated porous $\mathrm{TiO} 2$ films as an effective $p$-n junction with enhanced photocatalytic activity, Journal of the American Ceramic Society 100(4) (2017) 1339-1349.

[34] J. Xu, Y. Ao, D. Fu, C. Yuan, Synthesis of Bi2O3-TiO2 composite film with high-photocatalytic activity under sunlight irradiation, Applied Surface Science 255(5, Part 1) (2008) 2365-2369.

[35] N. Lakshmana Reddy, S. Emin, M. Valant, M.V. Shankar, Nanostructured Bi2O3@TiO2 photocatalyst for enhanced hydrogen production, International Journal of Hydrogen Energy 42(10) (2017) 6627-6636.

[36] Y. Huang, Y. Wei, J. Wang, D. Luo, L. Fan, J. Wu, Controllable fabrication of Bi2O3/TiO2 heterojunction with excellent visible-light responsive photocatalytic performance, Applied Surface Science 423 (2017) 119-130.

[37] P.J. Kelly, R.D. Arnell, Magnetron sputtering: a review of recent developments and applications, Vacuum 56(3) (2000) 159-172.

[38] M. Ratova, P. Kelly, G. West, L. Tosheva, A Novel Technique for the Deposition of Bismuth Tungstate onto Titania Nanoparticulates for Enhancing the Visible Light Photocatalytic Activity, Coatings 6(3) (2016) 29.

[39] A. Nitta, M. Takase, M. Takashima, N. Murakami, B. Ohtani, A fingerprint of metal-oxide powders: energy-resolved distribution of electron traps, Chemical Communications 52(81) (2016) 12096-12099.

[40] B. Ohtani, Physicochemical Mechanistic Studies on Photocatalysis-Extension of Semiconductor Photoelectrochemistry Concept beyond Its Limitation, Electrochemistry 86(6) (2018) 273-280.

[41] J.G. Highfield, P. Pichat, Photoacoustic study of the influence of platinum loading and bulk doping with chromium III ions on the reversible photochromic effect in titanium dioxide. Correlation with photocatalytic properties, New Journal of Chemistry 13 (1989) 5.

[42] M. Ratova, P.J. Kelly, G.T. West, L. Tosheva, M. Edge, Reactive magnetron sputtering deposition of bismuth tungstate onto titania nanoparticles for enhancing visible light photocatalytic activity, Applied Surface Science 392 (2017) 590-597.

[43] B. Tryba, S. Jafari, M. Sillanpää, A. Nitta, B. Ohtani, A.W. Morawski, Influence of TiO2 structure on its photocatalytic activity towards acetaldehyde decomposition, Applied Surface Science 470 (2019) 376-385.

[44] F. Sieland, J. Schneider, D.W. Bahnemann, Photocatalytic activity and charge carrier dynamics of TiO2 powders with a binary particle size distribution, Physical Chemistry Chemical Physics 20(12) (2018) 8119-8132.

[45] R. Enríquez, A.G. Agrios, P. Pichat, Probing multiple effects of TiO2 sintering temperature on photocatalytic activity in water by use of a series of organic pollutant molecules, Catalysis Today 120(2) (2007) 196-202.

[46] E. Filippo, C. Carlucci, A.L. Capodilupo, P. Perulli, F. Conciauro, G.A. Corrente, G. Gigli, G. Ciccarella, Enhanced Photocatalytic Activity of Pure Anatase Tio2 and Pt-Tio2 Nanoparticles Synthesized by Green Microwave Assisted Route, Materials Research 18 (2015) 473-481. 
[47] H. Cheng, B. Huang, J. Lu, Z. Wang, B. Xu, X. Qin, X. Zhang, Y. Dai, Synergistic effect of crystal and electronic structures on the visible-light-driven photocatalytic performances of $\mathrm{Bi} 2 \mathrm{O} 3$ polymorphs, Physical Chemistry Chemical Physics 12(47) (2010) 15468-15475.

[48] S.J. Rowley-Neale, M. Ratova, L.T.N. Fugita, G.C. Smith, A. Gaffar, J. Kulczyk-Malecka, P.J. Kelly, C.E. Banks, Magnetron Sputter-Coated Nanoparticle MoS2 Supported on Nanocarbon: A Highly Efficient Electrocatalyst toward the Hydrogen Evolution Reaction, ACS Omega 3(7) (2018) 72357242.

[49] S. Swetha, S.M. Santhosh, R. Geetha Balakrishna, Synthesis and Comparative Study of NanoTiO2 Over Degussa P-25 in Disinfection of Water, Photochemistry and Photobiology 86(3) (2010) 628-632.

[50] F. Moulis, J. Krýsa, Photocatalytic degradation of acetone and methanol in a flow-through photoreactor with immobilized TiO2, Research on Chemical Intermediates 41(12) (2015) 9233-9242. [51] M. Le Bechec, N. Kinadjian, D. Ollis, R. Backov, S. Lacombe, Comparison of kinetics of acetone, heptane and toluene photocatalytic mineralization over TiO2 microfibers and Quartze ${ }^{\circledR}$ mats, Applied Catalysis B: Environmental 179 (2015) 78-87.

[52] J. Taranto, D. Frochot, P. Pichat, Photocatalytic air purification: Comparative efficacy and pressure drop of a TiO2-coated thin mesh and a honeycomb monolith at high air velocities using a $0.4 \mathrm{~m} 3$ close-loop reactor, Separation and Purification Technology 67(2) (2009) 187-193.

[53] M.D. Hernandez-Alonso, F. Fresno, S. Suarez, J.M. Coronado, Development of alternative photocatalysts to TiO2: Challenges and opportunities, Energy \& Environmental Science 2(12) (2009) 1231-1257.

[54] A. Nitta, M. Takashima, N. Murakami, M. Takase, B. Ohtani, Reversed double-beam photoacoustic spectroscopy of metal-oxide powders for estimation of their energy-resolved distribution of electron traps and electronic-band structure, Electrochimica Acta 264 (2018) 83-90. [55] A. Nitta, M. Takashima, M. Takase, B. Ohtani, Identification and characterization of titania photocatalyst powders using their energy-resolved distribution of electron traps as a fingerprint, Catalysis Today 321-322 (2019) 2-8.

[56] B. Ohtani, A. Nitta, Y. Murakami, M. Takashima, Effect of pretreatment on energy-resolved distribution of electron traps on metal-oxide surfaces, to be published. 